\title{
Dynamics of digital ulcers in systemic sclerosis
}

\author{
CARMEN BOBEICĂ $\breve{1}^{1,2}$, ALIN LAURENȚIU TATU ${ }^{3,4}$, \\ MIHAELA CRĂESCU ${ }^{2,5}$ and LAURA GHEUCA-SOLOVĂSTRU ${ }^{6,7}$
}

\author{
${ }^{1}$ Department of Dermato-Venereology, Doctoral School, University of Medicine and Pharmacy 'Gr. T. Popa' Iași, \\ 700115 Iași; ${ }^{2}$ Department of Morphological and Functional Sciences, 'Dunărea de Jos’ University of Galați, \\ Faculty of Medicine and Pharmacy; ${ }^{3}$ Department of Clinical Dermato-Venereology, 'Dunărea de Jos' University of Galați, \\ Faculty of Medicine and Pharmacy, ReForm UDJ, 800216 Galați; ${ }^{4}$ Department of Clinical Dermato-Venereology, \\ 'Sf. Cuvioasă Parascheva' Infectious Diseases Clinical Hospital of Galați, 800179 Galați; \\ ${ }^{5}$ Department of Clinical Radiotherapy, 'Sf. Ap. Andrei’ Emergency Clinical Hospital of Galaţi, 800578 Galați; \\ ${ }^{6}$ Department of Clinical Dermato-Venereology, University of Medicine and Pharmacy 'Gr. T. Popa', \\ Faculty of Medicine and Pharmacy, 700115 Iași; ${ }^{7}$ Department of Clinical Dermato-Venereology, \\ ‘Sf. Spiridon’ Emergency Clinical Hospital of Iași, 700111 Iași, Romania
}

Received January 7, 2020; Accepted February 11, 2020

DOI: $10.3892 /$ etm.2020.8572

\begin{abstract}
Systemic sclerosis (SSc) is a collagenosis with insufficiently known etiopathogenesis, characterized by microvasculopathy and excessive fibrosis in the context of an autoimmune disorder. The incompletely elucidated pathogenesis and limited therapeutic options, disabling aspects, skin lesions and pain determine important functional and psychological deficiencies which affect the quality of life. It is imperative to observe and correlate individual clinical and paraclinical data to optimize disease management. A group of 22 patients diagnosed with SSc, hospitalized in a university clinic in Bucharest was included in an observational study. The evolution of digital ulcers was evaluated as an indicator of vasculopathy and their status and dynamics were correlated with clinical elements reflecting the fibrotic aspect of the disease. The present study shows that the Raynaud phenomenon is almost always present during the course of the disease, but its presence is not always associated with digital ulcers. The existing data in the literature show that fibrosis is subsequent to vasculopathy, but this study did not reveal causality between these two aspects of pathogenesis. The presence of microstomia and digital contracture was identified
\end{abstract}

Correspondence to: Dr Alin Laurențiu Tatu, Department of Clinical Dermato-Venereology, 'Dunărea de Jos' University of Galați, Faculty of Medicine and Pharmacy, ReForm UDJ, Str. Alexandru Ioan Cuza 35, 800216 Galați, Romania

E-mail:dralin_tatu@yahoo.com

Dr Mihaela Crăescu, Department of Morphological and Functional Sciences, 'Dunărea de Jos' University of Galați, Faculty of Medicine and Pharmacy, Str. Alexandru Ioan Cuza 35, 800216 Galați, Romania E-mail: dr.craescumihaela@yahoo.ro

Key words: systemic sclerosis, digital ulcers, microangiopaty, Raynaud's phenomen, microvasculopathy, microstomia in the presence of digital ulcers, but also in their absence. The etiopathogenic mechanisms with multiple unknown involved factors open the opportunity to investigate many aspects of $\mathrm{SSc}$ for optimal aiming of therapeutic interventions.

\section{Introduction}

SSc is a connective tissue disease with insufficiently known etiology, engraving of microvasculopathy and excessive cutaneous and visceral fibrosis. Studies show that the underlying pathogenic process is an immunological disorder from which targeted antibodies develop against 'self' structures. These autoantibodies trigger an excessive activation of the immune system and mainly of $\mathrm{T}$ cells (1) followed by inflammation at cellular level (2). SSc is part of the rare disease group, having an increasing incidence over the past two decades. Statistics show not only an increase in SSc incidence, but in autoimmune diseases as a whole (3).

Initially, reversible vasospasm of digital arteries is manifested by the appearance of Raynaud's phenomenon, followed by a disruption in finger pulp capillary architecture. In microangiopathy, ischemic disorders determine the appearance of digital ulcers and pitting scars (4). The disease pathogenesis is complex, partially known. Under the action of viruses, anti-endothelial antibodies, cytotoxic $\mathrm{T}$ lymphocytes and endothelial cells are activated early in SSc evolution and proliferation of the innermost vessels is triggered (5). It has been observed that microvascular endothelial dysfunction has as substrate the appearance of anti-endothelial antibodies and, mainly, the presence of anti-intercellular adhesion molecule (ICAM)-1 antibodies (6). Activated endothelial cells release proinflammatory cytokines and connective tissue growth factors, interleukin (IL)-1, IL-4, tumor necrosis factor (TNF)- $\alpha$, IL-6 and IL- 8 transforming growth factor (TGF)- $\beta$, which induce aberrant hyperactivated fibroblasts (7-11). Early endothelial cell involvement in SSc, leads to the destruction of blood capillaries with reduction in microvasculature through 
vascular repair and defective neoangiogenesis simultaneously with impaired lymphatic circulation followed by exudative accumulation and edema formation. Associations between lymphatic microvasculature damage with digital ulcer development and accentuation of cutaneous induration were observed, an induration which must be differentiated from that which appears in other disorders with sclerodermiform skin lesions, occurring in isolation or in the context of associated autoimmune diseases (12-14).

The presence of Raynaud's phenomenon reflects the affected vasodilation determined by the endothelial lesion, which has as substrate apoptosis of endothelial cells most likely under the action of anti-endothelial antibodies (15). The microvasculopathy lesions are expressed by the appearance of digital ulcers, telangiectasia, and at macrovascular level by kidney damage, pulmonary arterial hypertension and erectile dysfunction (16). Vascular occlusion results in the occurrence of ischemic-type phenomena, digital ulcers, which are difficult to treat with conventional treatments $(17,18)$; they are located on the tip of the fingers and on the extension surfaces of the joint, can become complicated with infections and sometimes with gangrene, thus requiring amputations or sympathectomy (19-21). Less often, impairment of microvasculature and digital arteries can produce critical digital ischemia (22). Cutolo et al (23) have described three capillaroscopic models of microvasculature impairment identified with the videocapillaroscope at the nailfold level. 'Early' pattern corresponds with the presence of dilated capillaries, 'giant capillaries' and hemorrhages. These changes are more pronounced in the 'active' capillary pattern, and 'late' pattern of the advanced SSc is characterized by alternating areas without capillaries, with areas where the capillaries are branched - 'bushy capillaries'.

Considering the multiple yet undetermined issues of this disease, we evaluated digital ulcers and Raynaud's phenomenon as an expression of peripheral vasculopathy, as well as acroosteolysis and microstomia, in order to establish correlations between vascular impairment and subsequent fibrosis We noted personal observations on this group of patients and established correlations between the identified clinical aspects. These correlations may be the basis for elucidating the etiopathogenesis of SSc, incompletely known. Previously, SSc benefitted only from symptomatic treatment with vasodilators, antifibrotic and immunosuppressive drugs, all with a modest therapeutic response and with often unpredictable evolution. Other interesting observations should be focused on relating to the microbioma changes on or around the lesional skin in scleroderma as in other diseases and also the possible adverse reactions that might have occurred after some topical or internal tratments of the comorbidities (24-34). Having the above in mind, numerous studies would be useful to clarify various aspects of the disease.

\section{Patients and methods}

An observational study was conducted on a group of 22 patients diagnosed with SSc with the help of the 2013 American College of Rheumatology (ACR)/European League Against Rheumatism (EULAR) criteria. For this study, the agreement was obtained from the Research Ethics Committee of the Faculty of Medicine in Iasi, as well as from the Ethics Council of the University Clinic in Bucharest. The patients were admitted between February and July 2019 to the internal medicine and rheumatology wards of a university clinic in Bucharest. The data was obtained from the clinical examination of the patients after they signed the informed consent and from the capillaroscopic examination of the nailfold. Acrosteolysis was evaluated clinically and radiologically and the oral opening was measured to quantify the degree of microstomia. With originality note, we used microstomia as an early indicator of skin fibrosis of the face observed before the appearance of tegumental induration in the hands and other segments evaluated by Rodnan score. The clinical and paraclinical data were observed and correlated to establish causality between vasculopathy and fibrosis. The data obtained was entered into an Excel file and analyzed statistically using Microsoft Excel, SPSS version 24.0, and the results are reported in the tables and graphs.

\section{Results}

Of the 22 patients, only 17 patients $(77.3 \%)$ had ulcers at one moment in time (Table I and Fig. 1). Of the 17 patients who presented with ulcers at one moment in time, 10 patients $(58.8 \%)$ had persistent digital ulcers despite the correct treatment and 7 patients $(41.2 \%)$ had a favorable ulcer evolution - healing and lack of recurrence (Table II and Fig. 2). The heterogeneous evolution of the disease was observed, a fact which is sometimes difficult to predict.

Of the 10 patients who had digital ulcers without healing, only 2 reached gangrene level without requiring amputation. Of the total 17 patients who presented with ulcers at one moment in time, 3 cases $(17.6 \%)$ were complicated with infections with Staphylococcus aureus identified through cultures from infected ulcers (Table III and Fig. 3). Of the 3 patients with infected digital ulcers, 2 patients had persistent ulcers after the resolution of the infectious process and only one patient had ulcers which were completely healed.

The model of impairment of blood capillaries in the fingers was studied using capillaroscopy (Table IV and Fig. 4) in order to establish a correlation with the status of digital ulcerations. Most patients had an active pattern on capillaroscopic examination $(59.1 \%)$ or active to late $(18.2 \%)$ and only 3 patients $(13.6 \%)$ were registered with a late pattern. Furthermore, 2 patients $(9.1 \%)$ with non-specific $\mathrm{ScS}$ pattern were identified.

By correlating the presence of acroosteolysis and digital ulcers (Fig. 5), it was found that of the 8 patients with acroosteolysis, 4 patients $(50.0 \%)$ had ulcers that remained active without healing, 3 patients $(37.5 \%)$ had ulcers that healed in time and 1 patient $(12.5 \%)$ had never suffered from digital ulcers. No correlation between the presence of digital ulcers and shortening of the distal phalanx seemed to exist.

Referring to the correlation between absence or presence of microstomia as an indicator of cutaneous fibrosis in association with digital ulcers, we observed that of the 2 patients who did not present with microstomia, 1 patient $(50.0 \%)$ had persistent ulcers without healing with gangrenous transformation, and 1 patient $(50.0 \%)$ had ulcers that healed in the course of the disease. Among those with microstomia, 9 patients $(45.0 \%)$ suffered from non-healing ulcers, of which 1 reached gangrene; 6 patients $(30.0 \%)$ had healing ulcers and 5 patients $(25.0 \%)$ never suffered from ulcers (Table V and Fig. 6). Thus, presence 
Table I. Status of digital ulcers - frequency distribution.

\begin{tabular}{lcc}
\hline Groups & $\begin{array}{c}\text { Absolute } \\
\text { frequency }\end{array}$ & $\begin{array}{c}\text { Percentage } \\
\text { frequency }\end{array}$ \\
\hline Valid & & \\
Without digital ulcers & 5 & 22.7 \\
Ulcers at a certain time & 17 & 77.3 \\
Total & 22 & 100.0 \\
\hline
\end{tabular}

Table II. Dynamics of digital ulcers - frequency distribution.

\begin{tabular}{lcc}
\hline Groups & $\begin{array}{c}\text { Absolute } \\
\text { frequency }\end{array}$ & $\begin{array}{c}\text { Percentage } \\
\text { frequency }\end{array}$ \\
\hline Valid & & \\
Persistent digital ulcers & 10 & 58.8 \\
Healed ulcers & 7 & 41.2 \\
Total & 17 & 100.0 \\
\hline
\end{tabular}

Table III. Evolution of digital ulcers - frequency distribution.

\begin{tabular}{lcc}
\hline Groups & $\begin{array}{c}\text { Absolute } \\
\text { frequency }\end{array}$ & $\begin{array}{c}\text { Percentage } \\
\text { frequency }\end{array}$ \\
\hline $\begin{array}{l}\text { Valid } \\
\text { Complicated ulcers }\end{array}$ & 3 & 17.6 \\
$\begin{array}{l}\text { with infections } \\
\text { Ulcers without } \\
\text { complications }\end{array}$ & 14 & 82.4 \\
Total & 17 & 100.0 \\
\hline
\end{tabular}

of microstomia as an indicator of cutaneous fibrosis, known to be subsequent to vascular impairment, does not correlate with status and evolution of digital ulcers, which represent a clue for peripheral microvasculopathy (Pearson $\chi^{2}=739, \mathrm{P}=0.691$ ).

Of the 6 patients with high degree microstomia $(4 \mathrm{~cm}$ oral opening), 2 patients (33.3\%) presented with persistent ulcers during the disease course, 3 patients (50.0\%) had healed ulcers and 1 patient (16.7\%) never presented with ulcers (Fig. 7). No correlation between the important limitation of oral opening and the status of digital ulcers was made.

Of the 9 patients who did not have finger contracture in the hands, and such, no limitations in finger flexion and extension, 2 patients (22.2\%) presented with persistent ulcers, 3 patients (33.3\%) had healed ulcers during the disease course and 4 patients (44.4\%) never had ulcers (Table VI and Fig. 8). Moreover, there was no correlation between the contracture of the fingers and the status of digital ulcers. Of the 13 patients who had contracted fingers, 8 patients $(61.5 \%)$ had persistent active ulcers, 4 patients (30.8\%) had healing ulcers and 1 patient (7.7\%) never had digital ulcers (Figs. 9 and 10). Although there were clear differences, they did not reach the statistical significance threshold (Pearson $\chi^{2}=4.98, \mathrm{P}=0.082$ ).

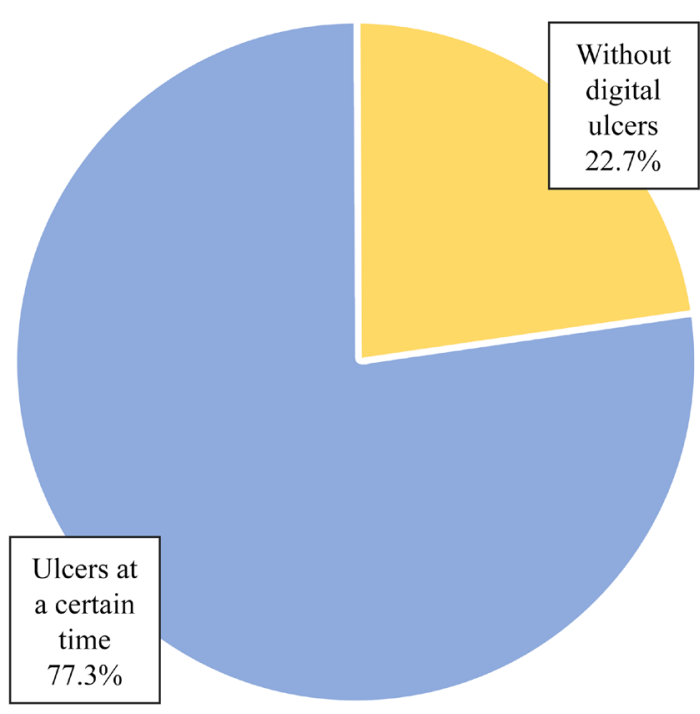

Figure 1. Status of digital ulcers - frequency distribution.

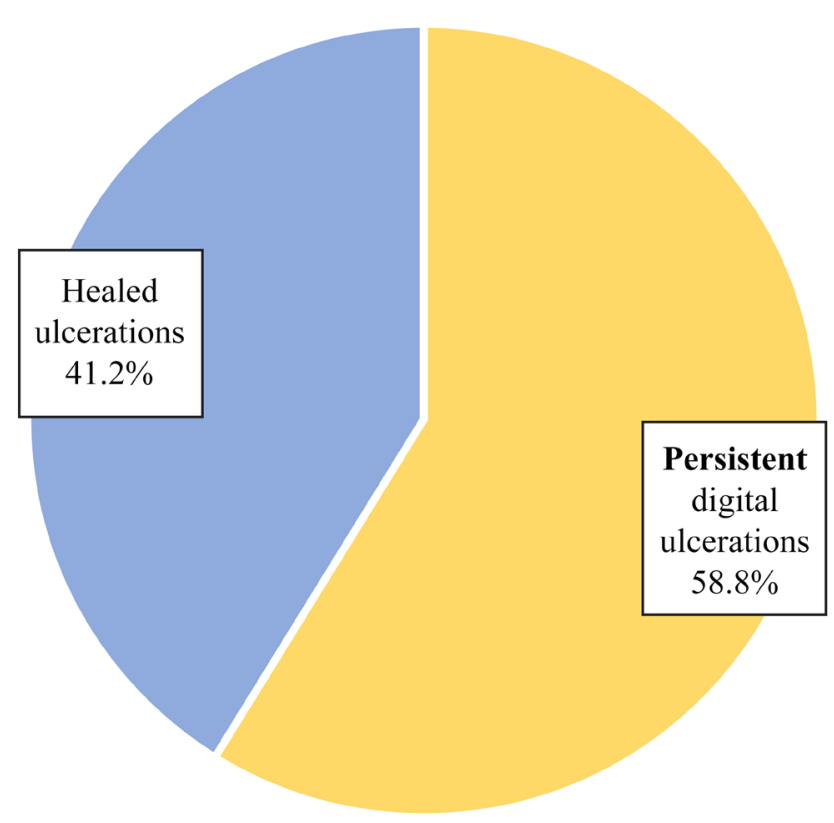

Figure 2. Dynamics of digital ulcers - frequency distribution.

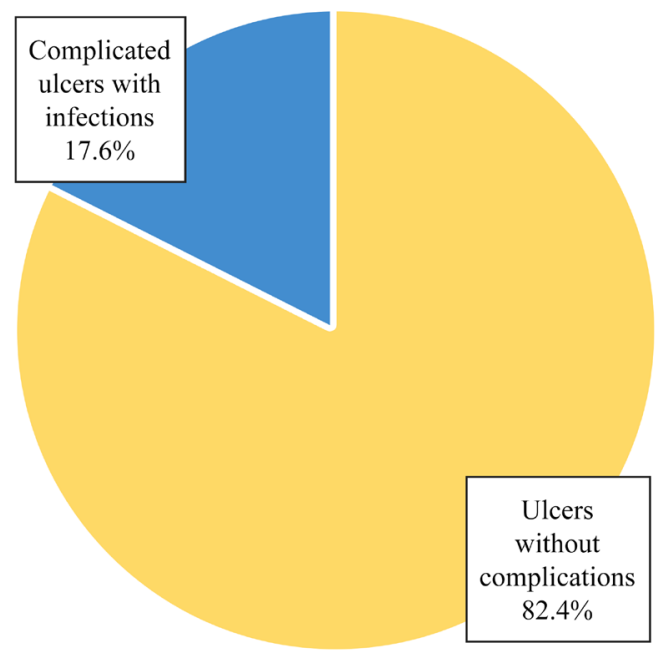

Figure 3. Evolution of digital ulcers - frequency distribution. 
Table IV. Pattern of blood capillary damage - frequency distributions.

\begin{tabular}{|c|c|c|c|c|c|c|}
\hline \multirow[b]{2}{*}{ Groups } & \multicolumn{2}{|c|}{0 - absent } & \multicolumn{2}{|c|}{1 - present } & \multicolumn{2}{|c|}{ Total } \\
\hline & $\mathrm{n}$ & $\%$ & $\mathrm{n}$ & $\%$ & $\mathrm{n}$ & $\%$ \\
\hline Capillary active pattern & 9 & 40.9 & 13 & 59.1 & 22 & 100.0 \\
\hline Active pattern to late & 18 & 81.8 & 4 & 18.2 & 22 & 100.0 \\
\hline Late pattern & 19 & 86.4 & 3 & 13.6 & 22 & 100.0 \\
\hline
\end{tabular}

Table V. Correlation of microstomia with digital ulcers.

\begin{tabular}{|c|c|c|c|c|c|c|c|c|}
\hline \multirow[b]{3}{*}{ Microstomia } & \multicolumn{7}{|c|}{ Ulcers } & \multirow{3}{*}{$\begin{array}{r}\text { Total } \\
\%\end{array}$} \\
\hline & \multicolumn{3}{|c|}{ Without healing } & \multicolumn{3}{|c|}{ Healed } & \multirow{2}{*}{$\begin{array}{c}\text { Absent } \\
n\end{array}$} & \\
\hline & $\mathrm{n}$ & $\%$ & $\mathrm{n}$ & $\%$ & $\mathrm{n}$ & $\%$ & & \\
\hline Absence & 1 & 50.0 & 1 & 50.0 & & & 2 & 100.0 \\
\hline Present & 9 & 45.0 & 6 & 30.0 & 5 & 25.0 & 20 & 100.0 \\
\hline Total & 10 & 45.5 & 7 & 31.8 & 5 & 22.7 & 22 & 100.0 \\
\hline
\end{tabular}

Table VI. Correlation between the presence of digital contracture and digital ulcers.

\begin{tabular}{|c|c|c|c|c|c|c|c|c|}
\hline \multirow[b]{3}{*}{ Contracture } & \multicolumn{7}{|c|}{ Ulcers } & \multirow{3}{*}{$\begin{array}{r}\text { Total } \\
\%\end{array}$} \\
\hline & \multicolumn{3}{|c|}{ Without healing } & \multicolumn{3}{|c|}{ Healed } & \multirow{2}{*}{$\begin{array}{c}\text { Absent } \\
n\end{array}$} & \\
\hline & $\mathrm{n}$ & $\%$ & $\mathrm{n}$ & $\%$ & $\mathrm{n}$ & $\%$ & & \\
\hline Absence & 2 & 22.2 & 3 & 33.3 & 4 & 44.4 & 9 & 100.0 \\
\hline Present & 8 & 61.5 & 4 & 30.8 & 1 & 7.7 & 13 & 100.0 \\
\hline Total & 10 & 45.5 & 7 & 31.8 & 5 & 22.7 & 22 & 100.0 \\
\hline
\end{tabular}

Active to late pattern

Active pattern

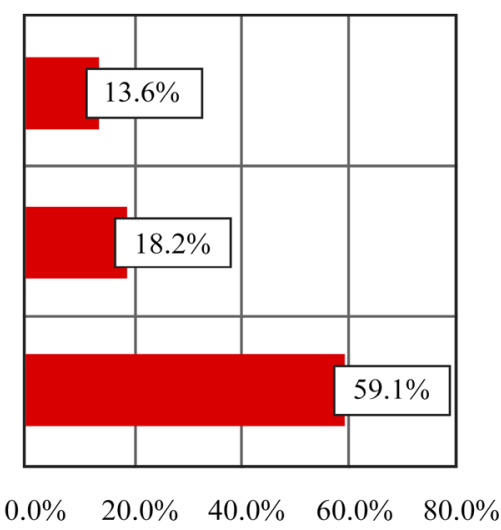

Figure 4. Pattern of blood capillary damage - frequency distributions.

\section{Discussion}

We conducted this observational study to create an overview of the skin condition of an SSc patient group in a university center; the small number of patients included in the study suggests the

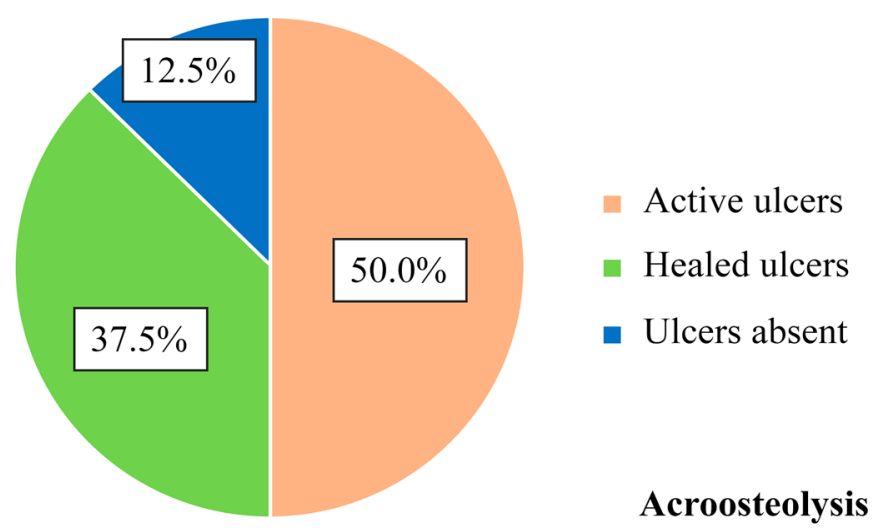

Figure 5. Correlation of acroosteolysis with digital ulcers - frequency distributions.

relatively low prevalence of this disease. Furthermore, SSc has a low incidence and the patients studied had different stages of disease through recruitment of both new cases and ones with $>10$ years of progression. SSc is part of the rare diseases group, 


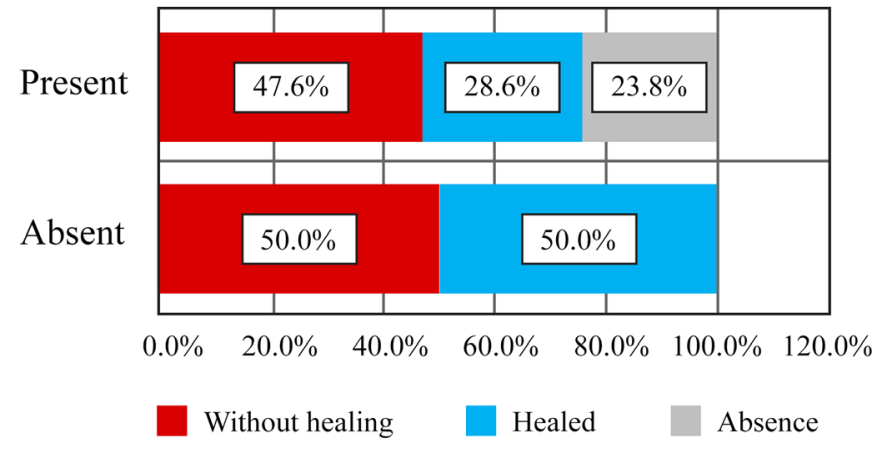

Figure 6. Correlation of microstomia with digital ulcers - frequency distributions.

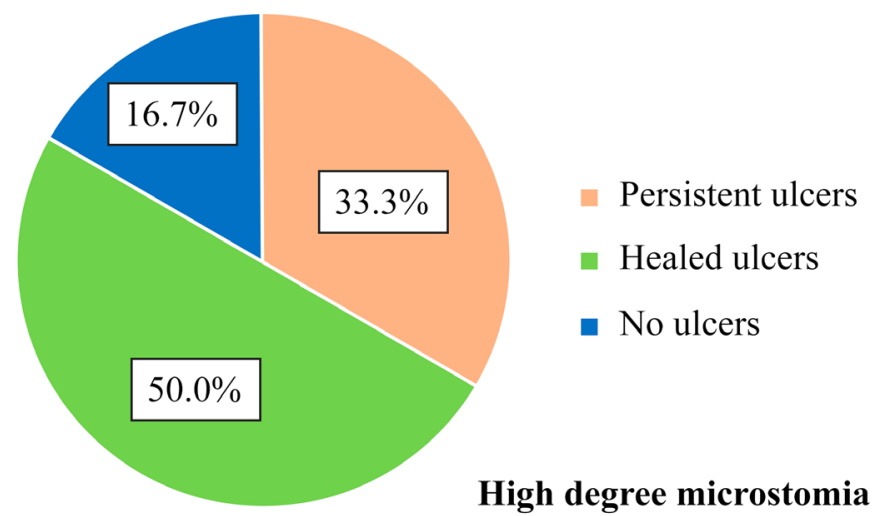

Figure 7. Correlation between the high degree microstomia and digital ulcers - frequency distribution.

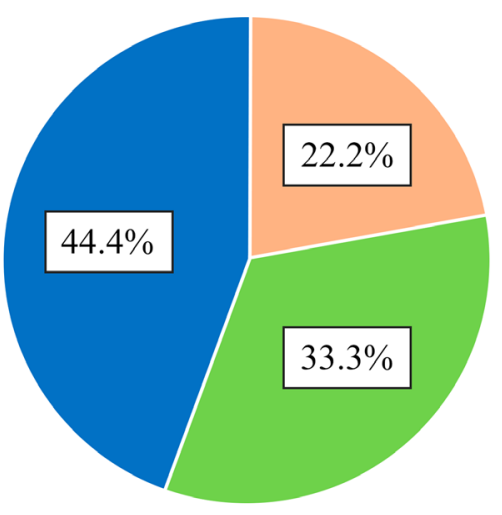

- Persistent ulcers

- Healed ulcers

Absent ulcers

Figure 8. Correlation between digital ulcers and absence of digital contracture - frequency distribution.

although in the recent years there has been a slight increase in incidence (3).

By analyzing the status of digital ulcers, we found that less than a quarter of patients had never suffered from digital ulcers, and of those with ulcers, more than half had persistent forms despite the correct treatment (35). Other patients had a favorable outcome with ulcer healing and no recurrence, a state most often registered under treatment with a dual endothelin receptor antagonist. The heterogeneous disease course is sometimes difficult to predict (36). Regarding the number and location of digital ulcers, the majority of patients had between 3 and 6 digital ulcers and patients with 1,2 or

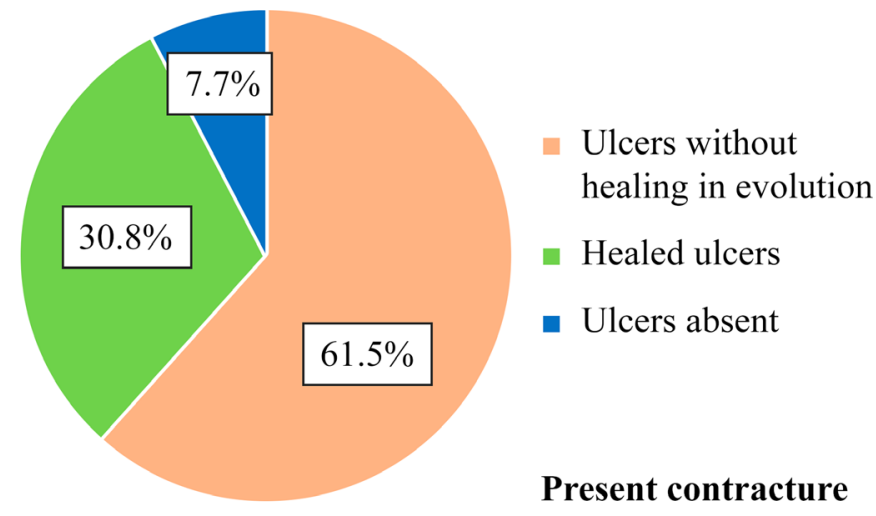

Figure 9. Correlation of digital ulcers with presence of digital contracture - frequency distribution.

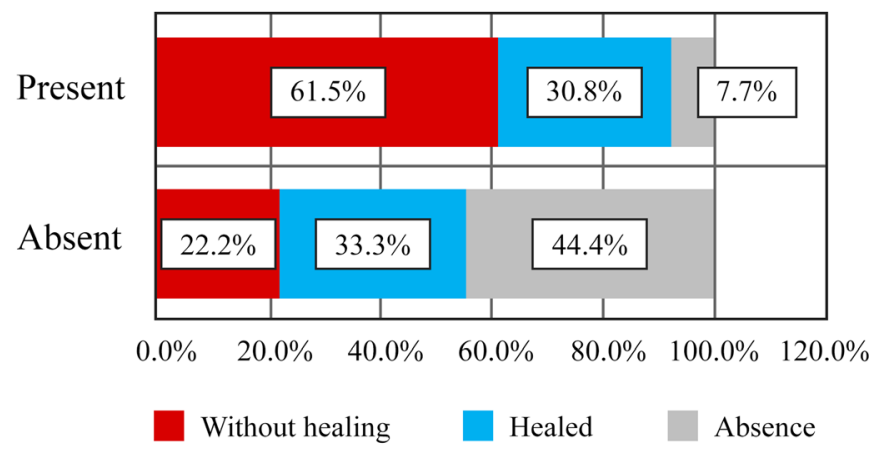

Figure 10. Correlation of digital ulcers with digital contracture - frequency distribution.

$>6$ ulcers were rarely identified; the most commonly affected were fingers II and III, probably due to their more frequent use in prehension. Of the patients who presented with digital ulcers at one time during the disease, only 3 cases were complicated by infections with Staphylococcus aureus and after antibiogram-guided antibiotic therapy, only one patient had completely healed ulcers, and the other 2 patients had persistent ulcers even after the infectious process was resolved. One can notice the low risk of infection of digital ulcers although they are located in an exposed area which is not covered and is frequently used. In the context of a disease with impaired immunity, the natural anti-infectious defense is preserved. Among patients who suffered from persistent digital ulcers, only one fifth had an unfavorable disease course towards gangrene, which was treated with no need for amputation. Most patients (with one exception) had Raynaud's phenomenon, reflecting the presence of peripheral microangiopathy; since one case did not present with digital ulcers. Absence of digital ulcers was found in the patient without Raynaud's phenomenon, but not all patients with Raynaud's phenomenon had digital ulcers. By analyzing the capillaroscopic pattern, only half of the patients with active pattern had persistent ulcers and only one third was associated with acroosteolysis (this was present in those with a late pattern). As in digital ulcers, acroosteolysis predominantly affected fingers II and III, being more frequently involved in prehension. I was noted that one of the patients having a nonspecific capillaroscopic pattern did not show Raynaud's 
phenomenon and never suffered from digital ulcers, probably due to an early disease stage. Studying the presence of microstomia and that of finger contracture in flexion as indicators of fibrosis, and the dynamics of digital ulcers as an indicator of digital microvasculopathy, no correlation between them was found although the causality between vascular and fibrosis is well known. However, the presence of a small degree of microstomia was observed as an early and more faithful indicator for skin fibrosis, which appeared earlier than the skin induration of the hands. In the early stages of the disease, before the appearance of tegumentary induration, Rodnan score being 0 , the presence of a small degree of microstomia already suggests the installation of cutaneous fibrosis based on our observations.

In conclusion, for now SSc remains an incurable disease with an etiology and pathogenesis that are not known in their entirety, with an invalidating course and an unfavorable psychological impact which diminishes the patient's quality of life; these reasons are a statement for the imperative need for future studies and observations on all aspects of the disease which might be useful for optimal management $(1,37,38)$.

\section{Acknowledgements}

Not applicable

\section{Funding}

No funding was received.

\section{Availability of data and materials}

The analyzed data sets generated during the present study are available from the corresponding author on reasonable request.

\section{Authors' contributions}

CB, ALT, MC and LS conceived and designed the study, provided the study materials or patient data and were responsible for the collection and assembly of the data, data analysis and interpretation, were involved in drafting and editing the manuscript. All the authors made an equal contribution to the article. All authors have read and approved the final manuscript.

\section{Ethics approval and consent to participate}

For this study, the agreement was obtained from the Research Ethics Committee of the Faculty of Medicine in Iasi, as well as from the Ethics Council of the University Clinic in Bucharest. All patients provided informed consent and approved the publication of data.

\section{Patient consent for publication}

Not applicable.

\section{Competing interests}

The authors declare that they have no competing interests.

\section{References}

1. Chihara M, Kurita M, Yoshihara Y, Asahina A and Yanaba K: Clinical significance of serum galectin-9 and soluble CD155 levels in patients with systemic sclerosis. J Immunol Res 2018: 9473243, 2018.

2. Cottin V and Brown KK: Interstitial lung disease associated with systemic sclerosis (SSc-ILD). Respir Res 20: 13, 2019.

3. Butt SA, Jeppesen JL, Fuchs C, Mogensen M, Engelhart M, Torp-Pedersen C, Gislason GH, Jacobsen S and Andersson C: Trends in incidence, mortality, and causes of death associated with systemic sclerosis in Denmark between 1995 and 2015: A nationwide cohort study. BMC Rheumatol 2: 36, 2018.

4. Friedrich S, Lüders S, Glimm AM, Werner SG, Schmittat G, Burmester GR, Backhaus M, Riemekasten G and Ohrndorf S: Association between baseline clinical and imaging findings and the development of digital ulcers in patients with systemic sclerosis. Arthritis Res Ther 21: 96, 2019.

5. McFarlane IM, Bhamra MS, Kreps A, Iqbal S, Al-Ani F, Saladini-Aponte C, Grant C, Singh S, Awwal K, Koci K, et al: Gastrointestinal manifestations of systemic sclerosis. Rheumatology (Sunnyvale) 8: 235, 2018.

6. Altorok N, Wang Y and Kahaleh B: Endothelial dysfunction in systemic sclerosis. Curr Opin Rheumatol 26: 615-620, 2014.

7. Liakouli V, Elies J, El-Sherbiny YM, Scarcia M, Grant G, Abignano G, Derrett-Smith EC, Esteves F, Cipriani P, Emery $\mathrm{P}$, et al: Scleroderma fibroblasts suppress angiogenesis via TGF- $\beta /$ caveolin-1 dependent secretion of pigment epithelium-derived factor. Ann Rheum Dis 77: 431-440, 2018.

8. Grigore O, Mihailescu AI, Solomon I, Boda D and Caruntu C: Role of stress in modulation of skin neurogenic inflammation. Exp Ther Med 17: 997-1003, 2019.

9. Ilie MA, Caruntu C, Lixandru D, Tampa M, Georgescu SR Constantin MM, Constantin C, Neagu M, Zurac SA and Boda D: In vivo confocal laser scanning microscopy imaging of skin inflammation: Clinical applications and research directions. Exp Ther Med 17: 1004-1011, 2019.

10. Ilie MA, Caruntu C, Tampa M, Georgescu SR, Matei C, Negrei C, Ion RM, Constantin C, Neagu M and Boda D: Capsaicin: Physicochemical properties, cutaneous reactions and potential applications in painful and inflammatory conditions. Exp Ther Med 18: 916-925, 2019.

11. Ghiţă MA, Căruntu C, Rosca AE, Căruntu A, Moraru L, Constantin C, Neagu M and Boda D: Real-time investigation of skin blood flow changes induced by topical capsaicin. Acta Dermatovenerol Croat 25: 223-227, 2017.

12. Manetti M, Pratesi S, Romano E, Rosa I, Bruni C, Bellando-Randone S, Guiducci S, Maggi E, Ibba-Manneschi L and Matucci-Cerinic M: Decreased circulating lymphatic endothelial progenitor cells in digital ulcer-complicated systemic sclerosis. Ann Rheum Dis 78: 575-577, 2019.

13. Tatu AL and Nwabudike LC: The treatment options of male genital lichen sclerosus et atrophicus: Treatments of genital lichen sclerosus. In: 14th National Congress of Urogynecology (Urogyn), Eforie, Romania, 262-264, 2017.

14. Tatu AL and Ionescu MA: Multiple autoimmune syndrome type III-thyroiditis, vitiligo and alopecia areata. Acta Endocrinol (Bucharest) 13: 124-125, 2017.

15. Kahaleh MB: Raynaud phenomenon and the vascular disease in scleroderma. Curr Opin Rheumatol 16: 718-722, 2004.

16. Denton CP: Advances in pathogenesis and treatment of systemic sclerosis. Clin Med (Lond) 15 (Suppl 6): s58-s63, 2015.

17. Codullo V, Distler O and Montecucco C: Pathophysiology of systemic sclerosis. In: Novel Insights into Systemic Sclerosis Management. Publisher Future Medicine Ltd., London, pp22-35, 2013.

18. Nwabudike LC and Tatu AL: Magistral prescription with silver nitrate and Peru Balsam in difficult to heal diabetic foot ulcers. Am J Ther 25: e679-e680, 2018.

19. Guillevin L, Hunsche E, Denton CP, Krieg T, Schwierin B, Rosenberg D and Matucci-Cerinic M; DUO Registry Group: Functional impairment of systemic scleroderma patients with digital ulcerations: Results from the DUO Registry. Clin Exp Rheumatol 31 (Suppl 76): 71-80, 2013.

20. Gheorghe I, Tatu AL, Lupu I, Thamer O, Cotar AI, Pircalabioru GG, Popa M, Cristea VC, Lazar V and Chifiriuc MC: Molecular characterization of virulence and resistance features in Staphylococcus aureus clinical strains isolated from cutaneous lesions in patients with drug adverse reactions. Rom Biotechnol Lett 22: 12321-12327, 2017. 
21. Ilie MA, Caruntu C, Lupu M, Lixandru D, Tampa M, Georgescu SR, Bastian A, Constantin C, Neagu M, Zurac SA, et al: Current and future applications of confocal laser scanning microscopy imaging in skin oncology. Oncol Lett 17: 4102-4111, 2019.

22. Herrick A and Muir L: Raynaud's phenomenon (secondary). BMJ Clin Evid: pii: 1125, 2014.

23. Cutolo M, Sulli A, Pizzorni C and Accardo S: Nailfold videocapillaroscopy assessment of microvascular damage in systemic sclerosis. J Rheumatol 27: 155-160, 2000.

24. Tatu AL and Cristea VC: Pityriasis folliculorum of the back thoracic area: Pityrosporum, keratin plugs, or demodex involved? J Cutan Med Surg 21: 441, 2017.

25. Nwabudike LC and Tatu AL: Response to - Chronic exposure to tetracyclines and subsequent diagnosis for non-melanoma skin cancer in a large Mid-Western US population. J Eur Acad Dermatol Venereol 32: e 159, 2018.

26. Tatu AL and Cristea VC: Unilateral blepharitis with fine follicular scaling. J Cutan Med Surg 21: 442, 2017.

27. Tatu AL and Nwabudike LC: Reply to: Kubiak K et al: Endosymbiosis and its significance in dermatology. J Eur Acad Dermatol Venereol 32: e346-e347, 2018.

28. Tatu AL, Clatici VG and Nwabudike LC: Rosacea-like demodicosis (but not primary demodicosis) and papulopustular rosacea may be two phenotypes of the same disease - a microbioma, therapeutic and diagnostic tools perspective. J Eur Acad Dermatol Venereol 33: e46-e47, 2019

29. Tatu AL, Ionescu MA and Nwabudike LC: Contact allergy to topical mometasone furoate confirmed by rechallenge and patch test. Am J Ther 25: e497-e498, 2018.

30. Tatu AL, Ciobotaru OR, Miulescu M, Buzia OD, Elisei AM, Mardare N, Diaconu C, Robu S and Nwabudike LC: Hydrochlorothiazide: Chemical structure, therapeutic, phototoxic and carcinogenetic effects in dermatology. Rev Chim (Bucharest) 69: 2110-2114, 2018
31. Nwabudike LC, Elisei AM, Buzia OD, Miulescu M and Tatu AL: Statins. A review on structural perspectives, adverse reactions and relations with non-melanoma skin cancer. Rev Chim (Bucharest) 69: 2557-2562, 2018.

32. Tatu AL, Elisei AM, Chioncel V, Miulescu M and Nwabudike LC Immunologic adverse reactions of $\beta$-blockers and the skin (Review). Exp Ther Med 18: 955-959, 2019.

33. Nwabudike LC, Miulescu M and Tatu AL: Case series of an alternative therapy for generalised lichen planus: Four case studies. Exp Ther Med 18: 943-948, 2019.

34. Ciobotaru OR, Lupu MN, Rebegea L, Ciobotaru OC, Duca OM, Tatu AL, Voinescu CD, Stoleriu G, Earar K and Miulescu M: Dexamethasone - chemical structure and mechanisms of action in prophylaxis of postoperative side effects. Rev Chim Buchar 70: 843-847, 2019.

35. Kanno Y, Shu E, Kanoh H and Seishima M: The antifibrotic effect of $\alpha 2$ AP neutralization in systemic sclerosis dermal fibroblasts and mouse models of systemic sclerosis. J Invest 136 : 762-769, 2016.

36. Vikse J, Gøransson LG and Norheim KB: Systemic capillary leak syndrome following bosentan treatment in a patient with systemic sclerosis. Scand J Rheumatol 48: 426-427, 2019.

37. Bobeică C, Crăescu M, Ancuța CI, Coman M and Nechita A: Experimental models for the study of systemic scleroderma. In: Annals of the University 'Dunarea de Jos' of Galati, Fascicle XVII. Galati University Press, 71-84, 2018.

38. Bobeică C, Vâță D, Stătescu L, Tăranu T, Popescu IA, Grăjdeanu AI and Gheucă-Solovăstru L: The quality of life for a patient with an autoimmune disease. Bull Integr Psychiatry XXV: 27-36, 2019.

This work is licensed under a Creative Common Attribution-NonCommercial-NoDerivatives 4.0 International (CC BY-NC-ND 4.0) License. 